\title{
Inhibition of the $\beta$-carbonic anhydrase from Streptococcus pneumoniae by inorganic anions and small molecules: Toward innovative drug design of antiinfectives?
}

\author{
Peter Burghout ${ }^{\mathrm{a}}$, Daniela Vullo ${ }^{\mathrm{b}}$, Andrea Scozzafava ${ }^{\mathrm{b}}$, Peter W. M. Hermans ${ }^{\mathrm{a}}$, Claudiu T. Supuran ${ }^{\mathrm{b}, *}$ \\ ${ }^{a}$ Laboratory of Pediatric Infectious Diseases, Radboud University Nijmegen Medical Centre, PO Box 9101 (internal mail 224), 6500 HB Nijmegen, The Netherlands \\ ${ }^{\mathrm{b}}$ Università degli Studi di Firenze, Polo Scientifico, Laboratorio di Chimica Bioinorganica, Rm. 188, Via della Lastruccia 3, 50019 Sesto Fiorentino, Florence, Italy
}

\section{A R T I C L E I N F O}

\section{Article history:}

Received 18 June 2010

Revised 9 November 2010

Accepted 10 November 2010

Available online 14 December 2010

\section{Keywords:}

Carbonic anhydrase

$\beta$-Class enzyme

Anion

Sulfamide

Sulfamic acid

Dithiocarbamates

Streptococcus pneumoniae

Antiinfectives

\begin{abstract}
A B S T R A C T
The Gram-positive bacterium Streptococcus pneumoniae is a human respiratory tract pathogen that contributes significantly to global mortality and morbidity. It was recently shown that this bacterial pathogen depends on a conserved $\beta$-carbonic anhydrase (CA, EC 4.2.1.1) for in vitro growth in environmental ambient air and during intracellular survival in host cells. Hence, it is to be expected that this pneumococcal carbonic anhydrase (PCA) contributes to transmission and pathogenesis of the bacterium, making it a potential therapeutic target. In this study, purified recombinant PCA has been further characterized kinetically and for inhibition with a series of inorganic anions and small molecules useful as leads. PCA has appreciable activity as catalyst for the hydration of $\mathrm{CO}_{2}$ to bicarbonate, with a $k_{\text {cat }}$ of $7.4 \times 10^{5} \mathrm{~s}^{-1}$ and $k_{\text {cat }} / K_{\mathrm{m}}$ of $6.5 \times 10^{7} \mathrm{M}^{-1} \mathrm{~s}^{-1}$ at an optimum $\mathrm{pH}$ of 8.4. Inorganic anions such as chloride, bromide, iodide, cyanate, selenocyanate, trithiocarbonate, and cyanide were effective inhibitors of PCA ( $K_{\mathrm{I}} \mathrm{S}$ of 21-98 $\left.\mu \mathrm{M}\right)$. Sulfamide, sulfamic acid, phenylboronic, phenylarsonic acid, and diethyldithiocarbamate showed inhibition constants in the low micromolar/submicromolar range $\left(K_{\mathrm{I}} \mathrm{S}\right.$ of $\left.0.61-6.68 \mu \mathrm{M}\right)$, whereas that of the sulfonamide acetazolamide was in the nanomolar range $\left(K_{\mathrm{I}} \mathrm{S} 89 \mathrm{nM}\right)$. In conclusion, our results show that PCA can effectively be inhibited by a range of molecules that could be interesting leads for obtaining more potent PCA inhibitors. PCA might be a novel target for designing antimicrobial drugs with a new mechanism of action.
\end{abstract}

(c) 2010 Elsevier Ltd. All rights reserved.

\section{Introduction}

The respiratory tract bacterium Streptococcus pneumoniae, or pneumococcus, is one of the most frequently encountered pathogens in humans, and is responsible for the death of approximately 1 million children under the age of five each year. ${ }^{1}$ It causes various infections, such as meningitis, septicemia, otitis media, sinusitis, and pneumonia. S. pneumoniae is a facultative anaerobe capable to adapt to the different environments it encounters during transmission, host colonization, and disease. An important variable in these niches is the level of carbon dioxide $\left(\mathrm{CO}_{2}\right)$, which could be as low as $0.038 \%$ in environmental ambient during transmission and over 5\% in the lungs and infected tissues. It is known for a long time that the complete depletion of environmental $\mathrm{CO}_{2}$ inhibits pneumococcal growth, ${ }^{2}$ suggesting that $\mathrm{CO}_{2}$ needs to be retained inside $S$. pneumoniae to support cellular processes. Recently, one of our groups showed that a mutant in the single, highly conserved pneumococcal $\beta$-carbonic anhydrase (PCA) renders in vitro growth of $S$. pneumoniae dependent on elevated $\mathrm{CO}_{2}$-levels or on supple-

\footnotetext{
* Corresponding author. Tel.: +39 055 4573005; fax: 390554573385.

E-mail address: claudiu.supuran@unifi.it (C.T. Supuran).
}

mentation with unsaturated fatty acids. These observations linked PCA-mediated $\mathrm{CO}_{2}$-fixation to fatty acid metabolism, and suggested that PCA is important for pneumococcus to cope with changes in nutrient availability during niche transition. ${ }^{3}$ Furthermore, we also observed a reduced survival of $S$. pneumoniae pca mutant strains inside host cells suggesting that PCA is also needed for pneumococcal adaptation to pathogenesis-related processes. ${ }^{3}$

Similar to PCA, carbonic anhydrases (CAs, EC 4.2.1.1) of various microbial pathogens have been implicated in cell survival and pathogenesis. ${ }^{4,5}$ It is therefore not surprising that CAs are considered as an emerging class of potential therapeutic targets also for the design of antiinfectives. ${ }^{5}$ CAs, which catalyze the reversible hydration of carbon dioxide to bicarbonate $\left(\mathrm{CO}_{2}+\mathrm{H}_{2} \mathrm{O} \leftrightarrow \mathrm{HCO}_{3}{ }^{-}+\mathrm{H}^{+}\right)$, are ancient enzymes that were previously shown to be crucial in the regulation of acid-base balance in organisms all over the phylogenetic tree. $^{4-11}$ In addition, CAs participate in many other physiological processes, such as lipogenesis, gluconeogenesis, ureagenesis, bone resorption, production of body fluids, and transport of $\mathrm{CO}_{2}$ and $\mathrm{HCO}_{3}{ }^{-}$, tumorigenesis, etc. (in mammals), ${ }^{5,8}$ as well as $\mathrm{CO}_{2}$ concentrating mechanisms and photosynthesis (in plants, algae, some bacteria, and diatoms) ${ }^{6,7}$ Five genetically distinct classes of these enzymes have been identified so far: the $\alpha, \beta, \gamma, \delta$, and $\zeta$-CAs. ${ }^{4-8}$ 
Among them, the $\beta$-CAs seem to be the most common class, ${ }^{4,5}$ in various organisms all over the phylogenetic tree but absent in humans. ${ }^{4}$ The identification and characterization of $\beta$-CAs in a number of human pathogens, such as fungi/yeasts (e.g., Candida species, Cryptococcus neoformans, and Saccharomyces cerevisiae), ${ }^{9-12}$ and bacteria (e.g., Brucella suis, Helicobacter pylori, Mycobacterium tuberculosis, and Haemophilus influenzae), ${ }^{13-18}$ has already lead to novel antimicrobial compounds, with a new mechanism of action, as recently shown for a $\beta$-CA from B. suis, ${ }^{18}$ or for the enzymes from $H$. pylori. ${ }^{13}$

Continuing our interest in finding and characterizing members of the $\beta$-CA family in pathogenic organisms for the development of novel antimicrobial compounds, we report the kinetic characterization PCA from S. pneumoniae. We also report the first inhibition study of this enzyme with inorganic anions, various small compounds known to target the metal ion in metalloenzymes like CAs, and the broad-range CA inhibitory compound acetazolamide (AZA).

\section{Results and discussion}

\subsection{Catalytic activity of PCA}

In the previous work ${ }^{3}$ the catalytic activity for the physiologic reaction, that is, $\mathrm{CO}_{2}$ hydration to bicarbonate and protons, has been evidenced for PCA, but the kinetic parameters were not determined. Thus, we investigate here in detail the properties of this new and interesting representative of the $\beta$-CA class.

In Figure 1, we have aligned the PCA protein sequence with various $\beta$-CAs from archaeal, bacterial or fungal origin. ${ }^{7,9,12-18}$ It may be observed that PCA has all the amino acids residues typical of catalytically active $\beta$-CAs, which are involved in the catalytic cycle of this class of enzymes: $^{4}$ (i) the $\mathrm{Zn}(\mathrm{II})$ binding residues Cys36, His89, and Cys92; $4,5,11$ and (ii) the Asp38-Arg40 catalytic dyad, involved in the opening/closing of the active site. ${ }^{14}$ Indeed, unlike $\alpha-, \gamma-$, and $\delta$-CAs, for which the $\mathrm{Zn}(\mathrm{II})$ is coordinated by three His residues and a water molecule/hydroxide ion, in the case of the $\beta$-class CAs the metal ion coordination is more complicated, being generally achieved by one His and two Cys residues., ${ }^{4,511,14}$ However, some $\beta$-class enzymes have four protein zinc ligands, that is, one His, two Cys, and one Asp coordinated to $\mathrm{Zn}(\mathrm{II}) .{ }^{14}$ For these enzymes no water coordinated to the metal ion is present at $\mathrm{pH}$ values $<8$, as shown in an excellent crystallographic work from Jones' group on the mycobacterial enzymes Rv3558c and Rv1284. ${ }^{14}$ However, at $\mathrm{pH}$ values $>8$, a conserved Arg residue in all $\beta$-CAs investigated so far (belonging to the above-mentioned catalytic dyad) ${ }^{14}$ makes a salt bridge with the Asp coordinated to $\mathrm{Zn}(\mathrm{II})$, liberating the fourth $\mathrm{Zn}$ (II) coordination position, which is then occupied by an incoming water molecule/hydroxide ion, acting thereafter as nucleophile in catalyzing $\mathrm{CO}_{2}$ hydration to bicarbonate. ${ }^{14}$

Based only on the amino acid sequence, it is however impossible to predict whether PCA will have a open or closed active site. In the open form, Cys36, Cys92, His89, and a catalytic water molecule/hydroxide ion would coordinate the $\mathrm{Zn}$ (II) ion, allowing the enzyme to be active over a broad pH-range. In the closed form, Aps38 would additionally coordinate to the $\mathrm{Zn}(\mathrm{II})$ ion as well, thereby replacing the water molecule/hydroxide ion needed for the catalytic activity. Only at $\mathrm{pH}$ values $>8$, when the conserved Arg40 residue makes a salt bridge with Asp38, the fourth $\mathrm{Zn}(\mathrm{II})$ coordination position may be available for the catalytic water molecule/hydroxide ion. ${ }^{14}$ To test if PCA has an open or closed active site, we accurately measured its catalytic activity at different $\mathrm{pH}$ values (Table 1 ). In Table 1 we show that the catalytic activity of PCA is absent at $\mathrm{pH}$ of 6.5 and 7.5 , being very low at $\mathrm{pH} 8$, and steadily increasing at higher $\mathrm{pH}$ values ( 8.2 and 8,4 ), which implies that PCA probably has a closed active (with Asp38 is coordinated to the metal ion) at $\mathrm{pH}$ values under 8 . It should be noted that the optimum $\mathrm{pH}$ for the hydration of $\mathrm{CO}_{2}$ correlates very well physiological conditions in which PCA is optimally expressed. Expression of the pca gene is induced in the pneumococcal X-state, ${ }^{19 a}$ which is a physiological condition that allows for genetic transformation, biofilm formation, and an adequate response to environmental stress. ${ }^{19 b, c}$ During the X-state, the intracellular $\mathrm{pH}$ in S. pneumoniae rises to about $\mathrm{pH} 8.3$ as result of increased glycolysis and sodium $\left(\mathrm{Na}^{+}\right)$fluxes. ${ }^{19 d, e}$ Whether PCA is needed in these conditions to compensate for further alkalinization of the cytosol, providing $\mathrm{HCO}_{3}^{-}$to match with intracellular levels of $\mathrm{Na}^{+}$, or to sustain metabolic pathways needed in the X-state remains to be investigated. It should be anyhow mentioned that the $\mathrm{CO}_{2}$ hydrase activity of PCA and of any other CA belonging to the various enzyme classes is increasing with the $\mathrm{pH}$ as the alkaline medium is favorable to the formation of the zinc hydroxide species of the enzyme. However at $\mathrm{pH}$ values $>8.5$ the uncatalyzed $\mathrm{CO}_{2}$ hydrations starts to drastically compete with the reaction catalyzed by the enzymes. These are the two reasons why we did not measure PCA catalytic activity at $\mathrm{pH}$ values higher than 8.4.

Next, we zoomed in at the PCA kinetic parameters for the $\mathrm{CO}_{2}$ hydration reaction at $\mathrm{pH} 8.4$, and compared it to that of $\alpha$-CAs of human (h) origin (hCAI and hCAII) and $\beta$-CAs from the archaeon Methanobacterium thermoautotrophicum $(\mathrm{Cab})^{20}$ and the pathogenic fungus $C$. neoformans (Can2) ${ }^{11}$ investigated earlier (Table 1 ). These data showed that PCA has a significant activity as catalyst for the conversion of $\mathrm{CO}_{2}$ to bicarbonate, with a $k_{\text {cat }}$ of $7.4 \times 10^{5} \mathrm{~s}^{-1}$, and $k_{\text {cat }} / K_{\mathrm{m}}$ of $6.5 \times 10^{7} \mathrm{M}^{-1} \mathrm{~s}^{-1}$. Thus, PCA is a better catalyst for the physiological reaction than the human isoforms hCA I or the other two $\beta$-class enzymes with which it has been compared in the present work.

\subsection{Inhibition of PCA with inorganic anions and other small molecules}

Since $\mathrm{CAs}$ bind $\mathrm{HCO}_{3}{ }^{-}$, a substrate and inhibitor of these enzymes, ${ }^{4-8}$ inorganic anions do have a profound impact on their catalytic activity. Indeed, many classes of CAs, including the $\beta$ one, have been investigated for their interaction with anion inhibitors, 5,6,8,16,20-23 which, as in solution (e.g., cyanide, thiocyanate, azide, and other such metal complexing species), directly bind to the metal ion from the enzyme active site, in tetrahedral or trigonal bipyramidal geometry of the $\mathrm{Zn}(\mathrm{II})$ ion. ${ }^{5,6,8,11}$

Inhibition data of PCA with small inorganic anions was compared with inhibition data of the $\alpha$-CA isoforms hCA I and II (Table 2), as well as the $\beta$-class enzymes Cab and Can 2 reported earlier. ${ }^{12,19}$ Simple inorganic anions, including the physiological ones (such as chloride, bicarbonate, carbonate, and sulfate), as well as 'metal poisons' (cyanide, cyanate, thiocyanate, azide, hydrogen sulfide, bisulfite, nitrite, etc.) or anions with less affinity for metal ions in solution (tetrafluroborate, perchlorate, nitrate, fluoride, and heavier halides, among others) were included in this study. On the other hand, less investigated inorganic anions, such as stannate(IV), selenate(VI), tellurate(VI), perosmate(VIII), persulfate, pyrophosphate $(\mathrm{V})$, pyrovanadate $(\mathrm{V})$, tetraborate, perrhenate(VII), perrutenate(VII), persulfate, selenocyanate, iminodisulfonate, fluorosulfate, and trithiocarbonate were also included in this study, as they recently allowed us to discover new zinc-binding groups for designing potent $\alpha$-CA inhibitors. ${ }^{22}$

Similar to all other $\alpha$ - and $\beta$-CAs investigated so far, PCA was not sensitive to inhibition by perchlorate $\left(K_{\mathrm{I}}>200 \mathrm{mM}\right)$. Also sulfate was not very inhibitory (inhibition constant of $4.15 \mathrm{mM}$ ), but fluoride, thiocyanate, azide, carbonate, bicarbonate, nitrate, nitrite, hydrogen sulfide, bisulfite, pyrophosphate, and tetraborate were weak inhibitors, with $K_{\mathrm{I}} \mathrm{S}$ in the range of $0.32-0.85 \mathrm{mM}$. Halides other than fluoride, cyanate, and cyanide, were more potent inhibitors of PCA, with $K_{\mathrm{I}} \mathrm{S}$ in the range of $41-98 \mu \mathrm{M}$. Thus, for the ha- 
PCA

Rv1284

$\mathrm{CAB}$

CAN2

Rv3588C

PCA

Rv1284

$\mathrm{CAB}$

CAN2

Rv3588C

PCA

Rv1284

$\mathrm{CAB}$

CAN2

Rv3588C

PCA

Rv1284

$\mathrm{CAB}$

CAN2

Rv3588c

PCA

Rv1284

$\mathrm{CAB}$

CAN2

Rv3588C

--- - - - - - - - - - - - - MSYFEQFMQANQAYVAL---HGQLN------LPL 25

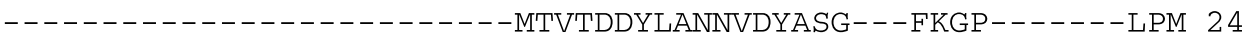

-------------------MRFVSMIIKDILRENQDFRFR---DLSD---------L 26

MPFHAEPLKPSDEIDMDLGHSVAAQKFKEIREVLEGNRYWARK---VTSEEPEFMAEQVK 57 -MPNTNPVAAWKALKEGNERFVAGRPQHPSQSVDHRAGLAA 40

$\star \quad$ :

KPKTRVAIVTCMDSRLH--VAQALGLALGDAHILRNAG---GRVTEDMIRSLVISQQQMG 80 PPSKHIAIVACMDARLD--VYRMLGIKEGEAHVIRNAG---CVVTDDVIRSLAISQRLLG 79 KHSPKLCIITCMDSRLIDLLERALGIGRGDAKVIKNAG---NIVDDGVIRSAAVAIYALG 83 GQAPNFLWIGCADSRVP--EVTIMARKPGDVFVQRNVANQFKPEDDSSQALLNYAIMNVG 115 GQKPTAVIFGCADSRVA--AEIIFDQGLGDMFVVRTAG---HVIDSAVLGSIEYAVTVLN 95

$$
\text { . } \mathrm{Z}{ }^{*}:{ }^{*}: \quad{ }^{*}: \quad: \text { : . . } \quad \text { : : }
$$

TREIVVLHHTDCG--AQTFENEPFQE---------YLKEELGVDVSDQDFLPFQDIE-E 127 TREIILLHHTDCG--MLTFTDDDFKR--------AIQDETGIRPT-WSPESYPDAV-E 125 VNEIIIVGHTDCG--MARLDEDLIVSRMRE-----LGVEEEVIENFSIDVLNPVGDEE-E 135 VTHVIVVVGHTGCGGCIAAFDQPLPTEENPGGTPLVRYLEPIIRLKHSLPEGSDVNDLIKE 175 VPLIVVLGHDSCGAVNAALAAINDGTLPGGYVRDVVERVAPSVLLGRRDGLSRVDEFEQR 155 . : : : : Z . Z*

SVREDMQLLIE-SPLIP----------DDVIISGAIYNVDTGSMTVVEL---------- 165

DVRQSLRRIEV-NPFVT----------KHTSLRGFVFDVATGKLNEVTP--------- 163

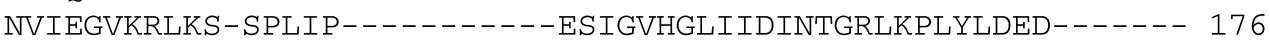
NVKMAVKNVVN-SPTIQGAWEQARKGEFREVFVHGWLYDLSTGNIVDLNVTQGPHPFVDD 234 HVHETVAILMARSSAISERIAG------GSLAIVGVTYQLDDGRAVLRDHIGNIGEEV-- 207

* : : $\quad \ldots:$ : $\quad$ * $\quad:$ *

$----165$

$----163$

$----176$

RVPRA 239

$-----207$

\begin{tabular}{|c|c|}
\hline$(100 \%$ & / \\
\hline$(37 \%$ & I \\
\hline ( $30 \%$ & / \\
\hline $16 \%$ & / \\
\hline $17 \%$ & / \\
\hline
\end{tabular}

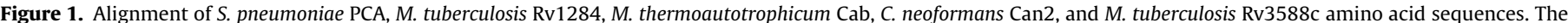

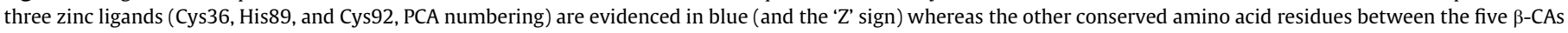

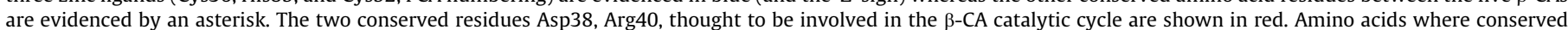

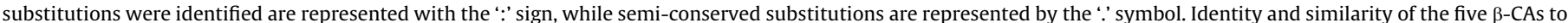
PCA are given in parentheses.

Table 1

Kinetic parameters for the $\mathrm{CO}_{2}$ hydration reaction catalyzed by the human cytosolic isozymes hCA I and II ( $\alpha$-class CAs) at $20^{\circ} \mathrm{C}$ and pH 7.5 in $10 \mathrm{mM}$ HEPES buffer and $20 \mathrm{mM} \mathrm{Na}_{2} \mathrm{SO}_{4}$, and the $\beta$-CAs Cab (from M. thermoautotrophicum), Can2 (from C. neoformans), and PCA (S. pneumoniae), respectively, measured at $20^{\circ} \mathrm{C}, \mathrm{pH} 5.6-8.4$ in $10 \mathrm{mM}$ Tris, HEPES or TAPS buffers and $20 \mathrm{mM} \mathrm{NaClO}_{4}{ }^{21}$

\begin{tabular}{lllll}
\hline Isozyme & Activity level & $k_{\text {cat }}\left(\mathrm{s}^{-1}\right)$ & $k_{\text {cat }} / K_{\mathrm{m}}\left(\mathrm{M}^{-1} \mathrm{~s}^{-1}\right)$ & $\mathrm{pH}$ \\
\hline hCA I $^{\mathrm{a}}$ & Moderate & $2.0 \times 10^{5}$ & $5.0 \times 10^{7}$ & 7.5 \\
hCA II $^{\mathrm{a}}$ & Very high & $1.4 \times 10^{6}$ & $1.5 \times 10^{8}$ & 7.5 \\
$\mathrm{Cab}^{\mathrm{b}}$ & Low & $3.1 \times 10^{4}$ & $1.8 \times 10^{6}$ & 8.4 \\
$\mathrm{Can2}^{\mathrm{b}}$ & Moderate & $3.9 \times 10^{5}$ & $4.3 \times 10^{7}$ & 8.4 \\
PCA $^{\mathrm{c}}$ & Inactive & 0 & 0 & 6.5 \\
PCA $^{\mathrm{c}}$ & Inactive & 0 & 0 & 7.5 \\
PCA $^{\mathrm{c}}$ & Very low & $1.1 \times 10^{4}$ & $1.9 \times 10^{5}$ & 8.0 \\
PCA $^{\mathrm{c}}$ & Moderate & $6.1 \times 10^{5}$ & $5.4 \times 10^{7}$ & 8.2 \\
PCA $^{\mathrm{c}}$ & Moderate & $7.4 \times 10^{5}$ & $6.5 \times 10^{7}$ & 8.4
\end{tabular}

a,b Data from Refs. 4,11,20.

c This work.

lides the inhibition power increased from fluoride to bromide and then slightly decreases again for iodide. This observation is very relevant, as, especially, chlorides are commonly used for buffer preparation. In fact, our first batch of purified PCA enzyme was only poorly active as a consequence of the presence of $50 \mathrm{mM}$ Tris- $\mathrm{HCl}$ in the final preparation (data not shown). ${ }^{3}$ It is also inter- esting to note that cyanide and cyanate are much more inhibitory than thiocyanate, although for other $\beta$-CAs, such as Cab and Can2, thiocyanate was a better inhibitor compared to cyanate. Cyanide showed weak inhibition of the $\beta$-CAs Cab and Can2 ( $K_{\mathrm{I}} \mathrm{S}$ of $13.56-$ $27.8 \mathrm{mM}$ ) while being an effective PCA inhibitor $\left(K_{\mathrm{I}}\right.$ of $\left.41 \mu \mathrm{M}\right)$. The less investigated inorganic anions incorporating heavy metal ions, as well as persulfate, peroxydisulfate, selenocyanate, fluorosulfate, and trithiocarbonate also showed significant PCA inhibitory activity, with inhibition constants in the range of 21-66 $\mu \mathrm{M}$ (Table 2). In this series of inorganic anions selenocyanate and trithiocarbonate were the best PCA inhibitors, with $K_{\mathrm{I}} \mathrm{S}$ of 21$22 \mu \mathrm{M}$. As the last anion incorporates a moiety amenable to the development of organic inhibitors, as already showed earlier, ${ }^{21}$ we investigated diethyldithiocarbamate, a compound incorporating the $\mathrm{CS}_{2}{ }^{-}$moiety present in trithiocarbonate as PCA inhibitor, together with several lead compounds that could serve as basis for the design of even more effective inhibitors (Table 3). Sulfamide, sulfamic acid, phenylboronic acid, and phenylarsonic acid are potent zinc-binding molecules that were previously shown to target several CAs in the low micromolar range. ${ }^{24,25}$

Data of Table 3 show that PCA was also inhibited in the low micromolar range by these compounds, with $K_{\mathrm{I}} \mathrm{S}$ in the range of $0.61-28.1 \mu \mathrm{M}$. Relevant for further research is the fact that phenylboronic acid and phenylarsonic acid inhibited rather well PCA and the other investigated $\beta$-CAs but not the human isoforms hCA I and 
Table 2

Inhibition constants of anionic inhibitors against isozymes hCA I, and II ( $\alpha$-CA class), and $\beta$-isozymes Cab (from the archaeon M. thermoautotrophicum) as well as Can2 (from C. neoformans) and PCA (from $S$. pneumoniae), for the $\mathrm{CO}_{2}$ hydration reaction, at $20^{\circ} \mathrm{C}^{21}$

\begin{tabular}{|c|c|c|c|c|c|}
\hline \multirow[t]{2}{*}{ Inhibitor $^{\mathrm{a}}$} & \multicolumn{5}{|c|}{$K_{\mathrm{I}}^{\mathrm{b}}(\mathrm{mM})$} \\
\hline & hCA I $^{\mathrm{c}}$ & hCA II ${ }^{\mathrm{c}}$ & $\mathrm{Cab}^{\mathrm{d}}$ & $\operatorname{Can} 2^{\mathrm{d}}$ & $\mathrm{PCA}^{\mathrm{e}}$ \\
\hline $\mathrm{F}^{-}$ & $>300$ & $>300$ & $>1000$ & 0.86 & 0.85 \\
\hline $\mathrm{Cl}^{-}$ & 6 & 200 & 152 & 0.92 & 0.052 \\
\hline $\mathrm{Br}^{-}$ & 4 & 63 & 42.1 & 1.00 & 0.046 \\
\hline $\mathrm{I}^{-}$ & 0.3 & 26 & 13.2 & 1.11 & 0.054 \\
\hline $\mathrm{CNO}^{-}$ & 0.0007 & 0.03 & 11.2 & 1.01 & 0.098 \\
\hline $\mathrm{SCN}^{-}$ & 0.2 & 1.60 & 0.52 & 0.94 & 0.38 \\
\hline $\mathrm{CN}^{-}$ & 0.0005 & 0.02 & 27.8 & 13.56 & 0.041 \\
\hline $\mathrm{N}_{3}^{-}$ & 0.0012 & 1.51 & 55.7 & 0.73 & 0.35 \\
\hline $\mathrm{HCO}_{3}{ }^{-}$ & 12 & 85 & 44.9 & 0.75 & 0.33 \\
\hline $\mathrm{CO}_{3}^{-}$ & 15 & 73 & 9.6 & 0.60 & 0.53 \\
\hline $\mathrm{NO}_{3}^{-}$ & 7 & 35 & 7.8 & 0.92 & 0.39 \\
\hline $\mathrm{NO}_{2}^{-}$ & 8.4 & 63 & 44.8 & 0.96 & 0.66 \\
\hline $\mathrm{HS}^{-}$ & 0.0006 & 0.04 & 0.70 & 0.60 & 0.35 \\
\hline $\mathrm{HSO}_{3}{ }^{-}$ & 18 & 89 & 45.1 & 0.71 & 0.57 \\
\hline $\mathrm{SnO}_{3}{ }^{2-}$ & 0.57 & 0.83 & nt & nt & 0.066 \\
\hline $\mathrm{SeO}_{4}^{2-}$ & 118 & 112 & nt & nt & 0.044 \\
\hline $\mathrm{TeO}_{4}{ }^{2-}$ & 0.66 & 0.92 & $\mathrm{nt}$ & nt & 0.049 \\
\hline $\mathrm{OsO}_{5}{ }^{2-}$ & 0.92 & 0.95 & nt & nt & 0.060 \\
\hline $\mathrm{S}_{2} \mathrm{O}_{7}^{2-}$ & 0.99 & 0.97 & nt & nt & 0.048 \\
\hline $\mathrm{P}_{2} \mathrm{O}_{7}^{4-}$ & 25.77 & 48.50 & $\mathrm{nt}$ & nt & 0.45 \\
\hline $\mathrm{V}_{2} \mathrm{O}_{7}^{4-}$ & 0.54 & 0.57 & $\mathrm{nt}$ & nt & 0.038 \\
\hline $\mathrm{B}_{4} \mathrm{O}_{7}^{2-}$ & 0.64 & 0.95 & $\mathrm{nt}$ & nt & 0.32 \\
\hline $\mathrm{ReO}_{4}^{-}$ & 0.110 & 0.75 & $\mathrm{nt}$ & nt & 0.039 \\
\hline $\mathrm{RuO}_{4}^{-}$ & 0.101 & 0.69 & $\mathrm{nt}$ & nt & 0.036 \\
\hline $\mathrm{S}_{2} \mathrm{O}_{8}{ }^{2-}$ & 0.107 & 0.084 & $\mathrm{nt}$ & nt & 0.046 \\
\hline $\mathrm{SeCN}^{-}$ & 0.085 & 0.086 & $\mathrm{nt}$ & nt & 0.022 \\
\hline $\mathrm{FSO}_{3}^{-}$ & 0.79 & 0.46 & nt & nt & 0.060 \\
\hline $\mathrm{CS}_{3}^{2-}$ & 0.0087 & 0.0088 & nt & nt & 0.021 \\
\hline $\mathrm{SO}_{4}^{2-}$ & 63 & $>200$ & $>200$ & 0.86 & 4.15 \\
\hline $\mathrm{ClO}_{4}^{-}$ & $>200$ & $>200$ & $>200$ & $>200$ & $>200$ \\
\hline
\end{tabular}

a As sodium salt.

b Errors were in the range of 3-5\% of the reported values, from three different assays.

c,d From Refs. 12,20.

e This work.

\section{Table 3}

Inhibition constants of small molecule compounds against isozymes hCA I and II ( $\alpha$-CA class), and $\beta$-isozymes Cab (from the archaeon $M$. thermoautotrophicum) as well as Can2 (from C. neoformans) and PCA (from S. pneumoniae), for the $\mathrm{CO}_{2}$ hydration reaction, at $20^{\circ} \mathrm{C}^{21}$

\begin{tabular}{lcclll}
\hline \multirow{2}{*}{ Inhibitor $^{\mathrm{a}}$} & \multicolumn{5}{c}{$K_{\mathrm{I}}^{\mathrm{b}}(\mu \mathrm{M})$} \\
\cline { 2 - 6 } & $\mathrm{hCA} \mathrm{I}^{\mathrm{c}}$ & hCA II $^{\mathrm{c}}$ & $\mathrm{Cab}^{\mathrm{d}}$ & $\mathrm{Can2}^{\mathrm{d}}$ & PCA $^{\mathrm{e}}$ \\
\hline $\mathrm{NH}\left(\mathrm{SO}_{3}\right)_{2}{ }^{2-}$ & 0.31 & 0.76 & $\mathrm{nt}$ & $\mathrm{nt}$ & 28.1 \\
$\mathrm{H}_{2} \mathrm{NSO}_{2} \mathrm{NH}_{2}$ & 0.31 & 1.13 & 103 & 0.99 & 4.25 \\
$\mathrm{H}_{2} \mathrm{NSO}_{3} \mathrm{H}$ & 0.021 & 0.39 & 44.0 & 8.22 & 6.68 \\
$\mathrm{Ph}-\mathrm{B}(\mathrm{OH})_{2}$ & 58.6 & 23.1 & 0.20 & 0.81 & 6.47 \\
$\mathrm{Ph}_{-} \mathrm{AsO}_{3} \mathrm{H}_{2}$ & 31.7 & 49.2 & 0.33 & 0.87 & 5.86 \\
$\mathrm{Et}_{2} \mathrm{NCS}_{2}{ }^{-}$ & 0.79 & 3.1 & nt & nt & 0.61 \\
$\mathrm{AZA}$ & 0.250 & 0.012 & 12.1 & 0.0105 & 0.089 \\
\hline
\end{tabular}

a As sodium salt.

b Errors were in the range of 3-5\% of the reported values, from three different assays;

c,d From Refs. 5,12,20.

e This work.

II. Sulfamide and sulfamic acid were also effective PCA inhibitors ( $K_{\mathrm{I}} \mathrm{S}$ of $4.25-6.68 \mu \mathrm{M}$ ), whereas iminodisulfonate was the least effective one among this small group of molecules, with an inhibition constant of $28.1 \mu \mathrm{M}$ (Table 3 ). However diethyldithiocarbamate was a very effective PCA inhibitor, with a $K_{\mathrm{I}}$ of $0.61 \mu \mathrm{M}$, whereas it has a roughly 5 times less affinity for hCA II, the phys- iologically dominant human isoform. Thus, this simple molecule may be considered as an excellent lead for developing better PCA inhibitors.

The best inhibitor for PCA investigated so far, appeared to be the clinically used sulfonamide acetazolamide, 5-acetamido-1,3,4-thiadiazole-2-sulfonamide (AZA). Unsubstituted sulfonamide inhibitors are known to bind with high affinity only to CAs. ${ }^{5}$ AZA showed efficient binding to the pneumococcal enzyme, with a $K_{\mathrm{I}} \mathrm{S}$ of $89 \mathrm{nM}$ (Table 3), which is better than the $K_{\mathrm{I}} \mathrm{S}$ of the slow human isoform hCA I (250 nM), but higher than that of the physiologically dominant hCA II, which is inhibited with a $K_{\mathrm{I}}$ of $12 \mathrm{nM}$. Furthermore, inhibition of other $\beta$-CAs with this sulfonamide are quite variable, with their archeal enzyme Cab having only micromolar affinity for the compound $\left(K_{\mathrm{I}}\right.$ of $\left.12.1 \mu \mathrm{M}\right)$, whereas the fungal one Can2 showing nanomolar affinity $\left(K_{\mathrm{I}}\right.$ of $\left.10.5 \mathrm{nM}\right) .{ }^{11}$ Interestingly, this data differ from the previous report ${ }^{3}$ in which AZA and ethoxzolamide (EZA) were shown to be unable to inhibit PCA (in vitro). ${ }^{3}$ However, in that study we were unaware of the inhibitory effect of chloride (present in the buffer solution), which might have interfered with the readout of our assays. ${ }^{3}$ Still, preliminary in vivo pneumococcal growth inhibition experiments with AZA and EZA did not render the wild type strain dependent on $\mathrm{CO}_{2}$-enriched medium (data not shown). This demonstrates that additional work on sulfonamides and other lead molecules with increased power to penetrate through the bacterial cell envelope as PCA inhibitors is a requisite for the successful use of this approach as a therapeutic tool to fight pneumococcal infection.

\subsection{Phylogenetic analysis}

PCA belongs to the $\beta$-CA class, which is a very divergent class of proteins, compared for example with the $\alpha$-CAs. ${ }^{4}$ Interestingly, the PCA gene that is present in the genomes of all S. pneumoniae strains available in the public databases and is very conserved (data not shown). This suggests that the gene is essential for pneumococcal dispersal throughout the population, and that effective PCA inhibitors might target most if not all pneumococcal strains. A phylogenetic tree build from an alignment of the amino acid sequences of $\beta$-CAs from various other bacterial, archeal, fungal, yeast, and nematode species (Fig. 2), revealed that PCA has only few close homologues. Pneumococcal CA is in the same phylogenetic branch as CAs of related streptococcal species, such as Streptococcus pyogenes. Besides, it clusters in the same clade ${ }^{4}$ as one type of CAs found in Mycobacterium and Candida species. This suggests that inhibitors that were recently designed for the $M$. tuberculosis Rv1284 CA, ${ }^{27}$ could be effective against PCA as well.

\section{Conclusion}

The $\beta$-CA from the bacterial pathogen Streptococcus pneumoniae was shown to be an efficient catalyst for the hydration of $\mathrm{CO}_{2}$ to bicarbonate with an optimum $\mathrm{pH}$ at 8.4. These characteristics are physiologically relevant, and helpful to determine the precise role of this protein for growth and survival of this respiratory tract pathogen during transmission and disease. The inhibition profile for PCA was different from that of other $\alpha$ - and $\beta$-class CAs investigated earlier for their interactions with anions and similar small molecule inhibitors. It is thus envisageable that stronger PCA inhibitors can be detected by using as lead molecules the most potent zinc-binding groups evidenced here (trithiocarbonate, selenocyanate, dithiocarbamates, and sulfonamides) and by exploring a larger array of sulfonamides. Work is in progress in these laboratories to assess a large number of such derivatives to detect inhibitors with possible in vivo use. 


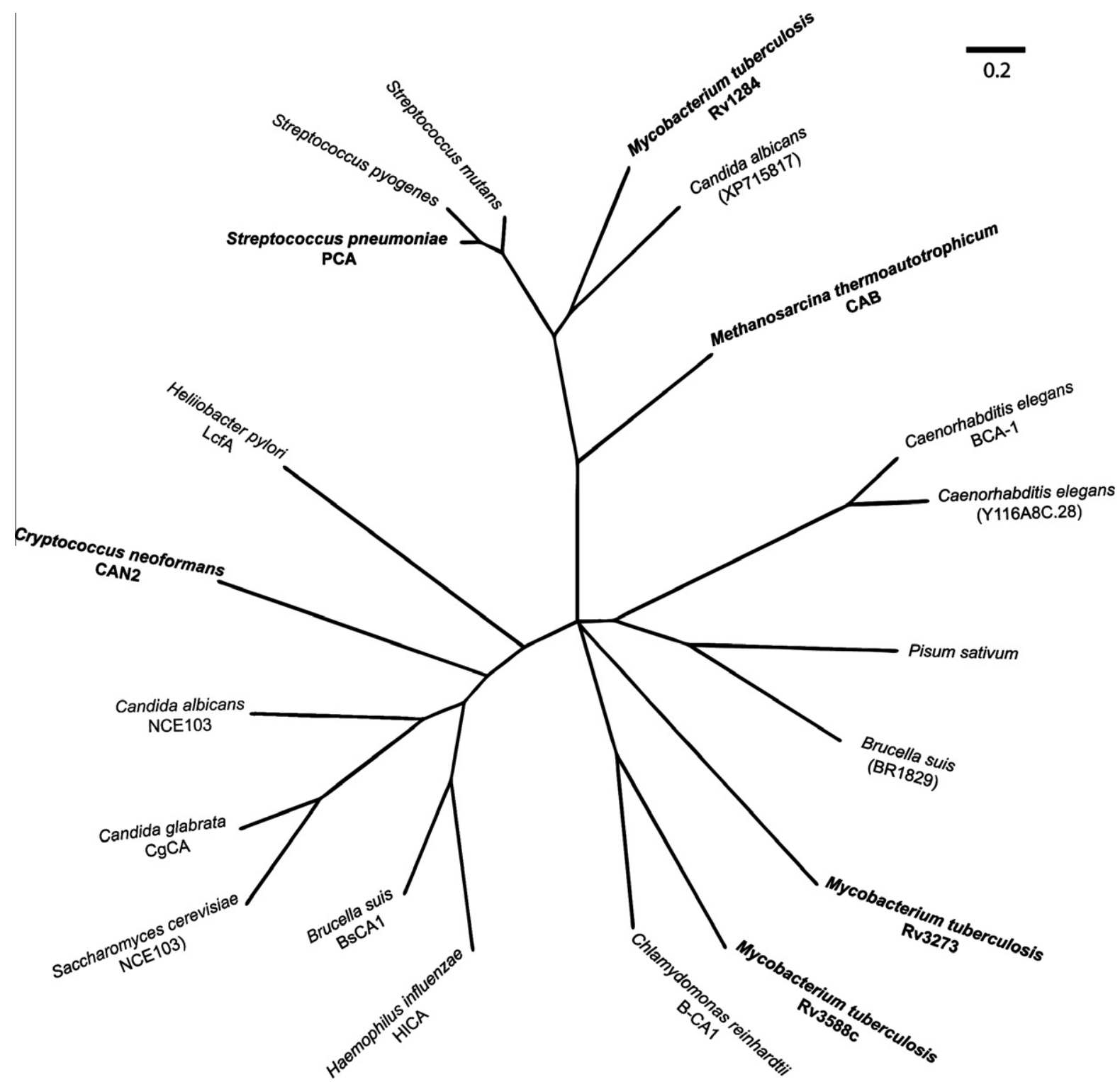

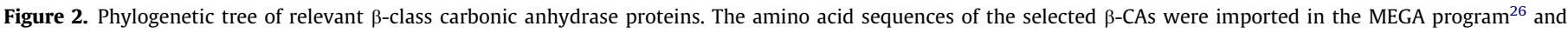

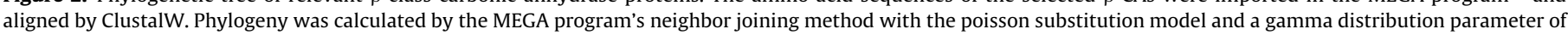

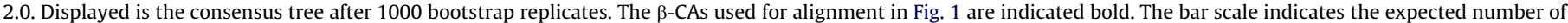
amino acid replacements per site.

\section{Experimental}

\subsection{Chemistry}

Inorganic sodium salt of anions from Tables 2 and 3, buffers, sulfamide, sulfamic acid, phenylarsonic acid, phenylphosphonic acid, sodium diethyldithiocarbamate, and other reagents were the highest grade purity available, from Sigma-Aldrich (Milan, Italy).

\subsection{PCA cloning, preparation, and purification}

Production and purification of PCA as a glutathione $S$-transferase fusion protein (GST-PCA) was performed as earlier described ${ }^{3}$ with only minor modifications. Briefly, an Escherichia coli BL21 (pWA4) culture was grown in $2 \times$ Luria Bertani broth at $37^{\circ} \mathrm{C}$ to an optical density at $600 \mathrm{~nm}$ of $0.6-0.8$, shifted to room temperature, and induced for GST-PCA production by addition of $0.1 \mathrm{mM}$ isopropyl- $\beta$-D-thiogalactopyranoside. After $4 \mathrm{~h}$, cells resuspended in lysis buffer $(50 \mathrm{mM}$ Tris- $\mathrm{HCl} \mathrm{pH} 7.5,300 \mathrm{mM} \mathrm{NaCl}, 0.5 \mathrm{mM}$ dithiothreitol, $1.5 \mathrm{mM} \mathrm{MgCl}_{2}, 0.2$ mM EDTA, 1\% Triton X-100) with $1 \times$ protease inhibitor mixture (Complete Mini; Roche Applied Science), lysed by sonication, and GST-PCA was affinity purified from the soluble fraction with Glutathione Sepharose 4 Fast Flow beads (GE Healthcare) at $4{ }^{\circ} \mathrm{C}$. Eluted GST-PCA was dialyzed against $10 \mathrm{mM}$ Tris- $\mathrm{HCl} \mathrm{pH}$ 7.5. The protein concentration in the solution was determined with a BCA Protein Assay Kit (Pierce). ${ }^{3}$

\subsection{CA activity and inhibition measurements}

An Applied Photophysics (Oxford, UK) stopped-flow instrument has been used for assaying the CA-catalyzed $\mathrm{CO}_{2}$ hydration activity by the method of Khalifah. ${ }^{21}$ Phenol red or $0,0^{\prime}$-phenanthroline (at a concentration of $0.2 \mathrm{mM}$ ) have been used as indicators, working at the absorbance maximum of $557 \mathrm{~nm}$ and 554, respectively, with 10-20 mM HEPES (pH 7.5, for $\alpha$-CAs) or Tris, HEPES or TAPS ( $\mathrm{pH}$ 
5.6-8.4 for $\beta$-CAs) as buffers, and $20 \mathrm{mM} \mathrm{Na}_{2} \mathrm{SO}_{4}$ (for $\alpha$-CAs) or $10-$ $20 \mathrm{mM} \mathrm{NaClO}{ }_{4}-$ for $\beta$-CAs (for maintaining constant the ionic strength), following the initial rates of the $\mathrm{CA}$-catalyzed $\mathrm{CO}_{2}$ hydration reaction for a period of $10-100 \mathrm{~s}^{21}$ The $\mathrm{CO}_{2}$ concentrations ranged from 1.7 to $17 \mathrm{mM}$ for the determination of the kinetic parameters and inhibition constants. For each inhibitor, at least six traces of the initial $5-10 \%$ of the reaction have been used for determining the initial velocity. The uncatalyzed rates were determined in the same manner and subtracted from the total observed rates. Stock solutions of inhibitor $(10 \mathrm{mM})$ were prepared in distilled-deionized water and dilutions up to $0.01 \mu \mathrm{M}$ were done thereafter with distilled-deionized water. Inhibitor and enzyme solutions were preincubated together for $15 \mathrm{~min}$ at room temperature prior to assay, in order to allow for the formation of the E-I complex. The inhibition constants were obtained by non-linear least-squares methods using PRISM 3, whereas the kinetic parameters for the uninhibited enzymes from Lineweaver-Burk plots, as reported earlier, ${ }^{11-13}$ and represent the mean from at least three different determinations.

\subsection{Alignment of protein sequences and phylogenetic analysis}

The amino acid sequences of the selected $\beta$-CAs were imported in the MEGA program ${ }^{26}$ and aligned by ClustalW. Phylogeny was calculated by the MEGA program's neighbor joining method with the poisson substitution model and a gamma distribution parameter of 2.0. Displayed is the consensus tree after 1000 bootstrap replicates. The $\beta$-CAs used for alignment in Figure 1 are indicated bold. The bar scale indicates the expected number of amino acid replacements per site.

\section{Acknowledgments}

This research was financed in part by a grant of the 6th Framework Programme of the European Union (DeZnIT project, to C.T.S. and A.S.) and by the Horizon Breakthrough Grant 93518023 of The Netherlands Genomics Initiative.

\section{References and notes}

1. O’Brien, K. L.; Wolfson, L. J.; Watt, J. P.; Henkle, E.; Deloria-Knoll, M.; McCall, N.; Lee, E.; Mulholland, K.; Levine, O. S.; Cherian, T. Lancet 2009, 374, 893.

2. Kempner, W.; Schlayer, C. J. Bacteriol. 1942, 43, 387.

3. Burghout, P.; Cron, L. E.; Gradstedt, H.; Quintero, B.; Simonetti, E.; Bijlsma, J. J.; Bootsma, H. J.; Hermans, P. W. J. Bacteriol. 2010, 192, 4054(PMID: 20525828).

4. (a) Smith, K. S.; Ferry, J. G. FEMS Microbiol. Rev. 2000, 24, 335; (b) Smith, K. S.; Jakubzick, C.; Whittam, T. S.; Ferry, J. G. Proc. Natl. Acad. Sci. U.S.A. 1999, 96, 15184; (c) Rowlett, R. S. Biochim. Biophys. Acta 2010, 1804, 362.

5. (a) Supuran, C. T. Nat. Rev. Drug Disc. 2008, 7, 168; (b) Supuran, C. T. Bioorg. Med. Chem. Lett. 2010, 20, 3467.

6. (a) Xu, Y.; Feng, L.; Jeffrey, P. D.; Shi, Y.; Morel, F. M. Nature 2008, 452, 56; (b) Cox, E. H.; McLendon, G. L.; Morel, F. M.; Lane, T. W.; Prince, R. C.; Pickering, I. J.; George, G. N. Biochemistry 2000, 39, 12128; (c) Lane, T. W.; Morel, F. M. Proc. Natl. Acad. Sci. U.S.A. 2000, 97, 4627.

7. Ferry, J. F. Biochim. Biophys. Acta 2010, 1804, 374.

8. (a) Supuran, C. T. Curr. Pharm. Des. 2008, 14, 641; (b) Supuran, C. T.; Di Fiore, A.; De Simone, G. Expert Opin. Emerg. Drugs 2008, 13, 383; (c) De Simone, G.; Di Fiore, A.; Supuran, C. T. Curr. Pharm. Des. 2008, 14, 655; (d) Mincione, F.;
Scozzafava, A.; Supuran, C. T. Antiglaucoma Carbonic Anhydrase Inhibitors as Ophthalmologic Drugs In Supuran, C. T., Winum, J. Y., Eds.; Drug Design of ZincEnzyme Inhibitors: Functional, Structural, and Disease Applications; Wiley: Hoboken, NJ, 2009; pp 139-154.

9. Elleuche, S.; Pöggeler, S. Microbiology 2010, 156, 23.

10. Isik, S.; Kockar, F.; Aydin, M.; Arslan, O.; Ozensoy Guler, O.; Innocenti, A.; Scozzafava, A.; Supuran, C. T. Bioorg. Med. Chem. 2009, 17, 1158.

11. Schlicker, C.; Hall, R. A.; Vullo, D.; Middelhaufe, S.; Gertz, M.; Supuran, C. T.; Mühlschlegel, F. A.; Steegborn, C. J. Mol. Biol. 2009, 385, 1207.

12. (a) Innocenti, A.; Mühlschlegel, F. A.; Hall, R. A.; Steegborn, C.; Scozzafava, A.; Supuran, C. T. Bioorg. Med. Chem. Lett. 2008, 18, 5066; (b) Innocenti, A.; Hall, R. A.; Schlicker, C.; Mühlschlegel, F. A.; Supuran, C. T. Bioorg. Med. Chem. 2009, 17 2654; (c) Innocenti, A.; Hall, R. A.; Schlicker, C.; Scozzafava, A.; Steegborn, C.; Mühlschlegel, F. A.; Supuran, C. T. Bioorg. Med. Chem. 2009, 17, 4503.

13. (a) Nishimori, I.; Minakuchi, T.; Morimoto, K.; Sano, S.; Onishi, S.; Takeuchi, H.; Vullo, D.; Scozzafava, A.; Supuran, C. T. J. Med. Chem. 2006, 49, 2117; (b) Nishimori, I.; Onishi, S.; Takeuchi, H.; Supuran, C. T. Curr. Pharm. Des. 2008, 14 622; (c) Nishimori, I.; Minakuchi, T.; Kohsaki, T.; Onishi, S.; Takeuchi, H.; Vullo, D.; Scozzafava, A.; Supuran, C. T. Bioorg. Med. Chem. Lett. 2007, 17, 3585.

14. (a) Suarez Covarrubias, A.; Larsson, A. M.; Hogbom, M.; Lindberg, J.; Bergfors, T.; Bjorkelid, C.; Mowbray, S. L.; Unge, T.; Jones, T. A. J. Biol. Chem. 2005, 280, 18782; (b) Suarez Covarrubias, A.; Bergfors, T.; Jones, T. A.; Hogbom, M. J. Biol. Chem. 2006, 281, 4993.

15. Carta, F.; Maresca, A.; Suarez Covarrubias, A.; Mowbray, S. L.; Jones, T. A.; Supuran, C. T. Bioorg. Med. Chem. Lett. 2009, 19, 6649.

16. (a) Innocenti, A.; Leewattanapasuk, W.; Mühlschlegel, F. A.; Mastrolorenzo, A.; Supuran, C. T. Bioorg. Med. Chem. Lett. 2009, 19, 4802; (b) Innocenti, A.; Leewattanapasuk, W.; Manole, G.; Scozzafava, A.; Mühlschlegel, F. A.; Supuran, C. T. Bioorg. Med. Chem. Lett. 2010, 20, 1701.

17. (a) Güzel, Ö.; Maresca, A.; Hall, R. A.; Scozzafava, A.; Mastrolorenzo, A Mühlschlegel, F. A.; Supuran, C. T. Bioorg. Med. Chem. Lett. 2010, 20, 2508; (b) Maresca, A.; Carta, F.; Vullo, D.; Scozzafava, A.; Supuran, C. T. Bioorg. Med. Chem. Lett. 2009, 19, 4929.

18. (a) Joseph, P.; Turtaut, F.; Ouahrani-Bettache, S.; Montero, J. L.; Nishimori, I.; Minakuchi, T.; Vullo, D.; Scozzafava, A.; Köhler, S.; Winum, J. Y.; Supuran, C. T.J. Med. Chem. 2010, 53, 2277; (b) Vullo, D.; Nishimori, I.; Scozzafava, A.; Köhler, S.; Winum, J. Y.; Supuran, C. T. Bioorg. Med. Chem. Lett. 2010, 20, 2178.

19. (a) Peterson, S. N.; Sung, C. K.; Cline, R.; Snesrud, E. C.; Luo, P.; Walling, J.; Li, H.; Mintz, M.; Tsegaye, G.; Burr, P. C.; Do, Y.; Ahn, S.; Gilbert, J.; Fleischmann, R. D.; Morrison, D. A. Mol Microbiol. 2004, 51, 1051; (b) Prudhomme, M.; Attaiech, L.; Sanchez, G.; Martin, B.; Claverys, J. P. Science 2006, 313, 89; (c) Oggioni, M. R. Trappetti, C.; Kadioglu, A.; Cassone, M.; Iannelli, F.; Ricci, S.; Andrew, P. W.; Pozzi, G. Mol. Microbiol. 2006, 61, 1196; (d) Clavé, C.; Trombe, M. C. FEMS Microbiol. Lett. 1989, 65, 113; (e) Lopez, A.; Clavé, C.; Capeyrou, E.; Lafontan, V.; Trombe, M. C. J. Gen. Microbiol. 1989, 135, 2189.

20. (a) Zimmerman, S.; Innocenti, A.; Casini, A.; Ferry, J. G.; Scozzafava, A.; Supuran, C. T. Bioorg. Med. Chem. Lett. 2004, 14, 6001; (b) Innocenti, A.; Zimmerman, S. Ferry, J. G.; Scozzafava, A.; Supuran, C. T. Bioorg. Med. Chem. Lett. 2004, 14 4563; (c) Zimmerman, S. A.; Ferry, J. G.; Supuran, C. T. Curr. Top. Med. Chem. 2007, 7, 901 .

21. Khalifah, R. G. J. Biol. Chem. 1971, 246, 2561.

22. (a) Innocenti, A.; Scozzafava, A.; Supuran, C. T. Bioorg. Med. Chem. Lett. 2009, 19, 1855; (b) Innocenti, A.; Scozzafava, A.; Supuran, C. T. Bioorg. Med. Chem. Lett. 2010, 20, 1548; (c) Temperini, C.; Scozzafava, A.; Supuran, C. T. Bioorg. Med. Chem. Lett. 2010, 20, 474.

23. (a) Bertucci, A.; Innocenti, A.; Zoccola, D.; Scozzafava, A.; Allemand, D.; Tambutté, S.; Supuran, C. T. Bioorg. Med. Chem. Lett. 2009, 19, 650; (b) Isik, S.; Kockar, F.; Arslan, O.; Ozensoy Guler, O.; Innocenti, A.; Supuran, C. T. Bioorg. Med. Chem. Lett. 2008, 18, 6327.

24. (a) Briganti, F.; Pierattelli, R.; Scozzafava, A.; Supuran, C. T. Eur. J. Med. Chem. 1996, 31, 1001; (b) Abbate, F.; Supuran, C. T.; Scozzafava, A.; Orioli, P.; Stubbs, M.; Klebe, G. J. Med. Chem. 2002, 45, 3583.

25. (a) Winum, J. Y.; Innocenti, A.; Scozzafava, A.; Montero, J. L.; Supuran, C. T. Bioorg. Med. Chem. 2009, 17, 3649; (b) Innocenti, A.; Winum, J. Y.; Hall, R. A.; Mühlschlegel, F. A.; Scozzafava, A.; Supuran, C. T. Bioorg. Med. Chem. Lett. 2009, 19, 2642.

26. Tamura, K.; Dudley, J.; Nei, M.; Kumar, S. Mol. Biol. Evol. 2007, 24, 1596.

27. Güzel, Ö.; Maresca, A.; Scozzafava, A.; Salman, A.; Balaban, A. T.; Supuran, C. T. J. Med. Chem. 2009, 52, 4063. 